seems to have a perfect duplex form.

In a recent issue of the Journal of Molecular Biology (85, 31-48; 1974) Miura, Watanabe and Sugiura report a similar analysis of silkworm cytoplasmic polyhedrosis virus. To avoid the difficulties in labelling silkworms with ${ }^{32} \mathrm{P}$ to produce radioactive virus, the isolated viral RNA was treated with phosphomonoesterase to remove any $5^{\prime}$ phosphates and then labelled in the $5^{\prime} \mathrm{OH}$ position using polynucleotide kinase and $\left[\gamma^{32} \mathrm{P}\right]$ ATP. The native double-stranded RNA molecules proved very difficult to label by this method, however, and to achieve efficient labelling Miura et al. first removed chemically two or three residues from the $3^{\prime}$ end of the molecules, thus exposing a short single-stranded $5^{\prime}$ terminal region. Presumably such single-stranded tails are much more accessible to enzymatic modification. The labelled molecules were then analysed by ribonuclease digestion followed by column chromatography. Two $5^{\prime}$ termini were found and were identified as $A^{*} \mathrm{GU}$ and GGC. The identity of the $5^{\prime}$ terminal base $\mathrm{A}^{*}$ is as yet uncertain but it is probably an adenosine residue with a modified $2^{\prime}$ $\mathrm{OH}$ group. Such modified bases, although a common feature in transfer RNA molecules, are rare in viral RNAs. The $5^{\prime}$ terminal sequences are consistent with perfect duplex formation in the SCPV genome since the same authors have previously identified cytosine and uridine as the $3^{\prime}$ terminal bases.

To determine whether all of the double-stranded genome segments contain both $5^{\prime}$ terminal sequences or if some fragments contain symmetrical ends, all of the ten genome segments were separated on polyacrylamide gels and then individually subjected to endgroup analysis. This showed that every fragment contains both sequences and suggests that each has the structure

$$
\begin{array}{lllll}
{ }^{5 \prime} \mathrm{A}^{*} \mathrm{G} \mathrm{U} & \ldots . & \mathrm{Pu} C \mathrm{C}^{3 \prime} \\
{ }^{3 \prime} \mathrm{U} & \mathrm{C} \mathrm{Pu} & \ldots . & \mathrm{C} & \mathrm{G} \mathrm{G}^{s^{\prime}}
\end{array}
$$

As with reovirus, silkworm cytoplasmic polyhedrosis virus particles contain an RNA-dependent RNA polymerase which actively transcribes the doublestranded RNA into messenger RNA in vitro. All ten mRNA molecules made in vitro by the reovirus enzyme begin with ppG (Banerjee, Ward and Shatkin, Nature new Biol., 230, 169$172 ; 1971)$. Further sequence data on highly labelled mRNA made from the smaller double stranded RNA segments has been presented by Nichols, Hay and Joklik (Nature new Biol., 235, 105-107; 1972). Some $5^{\prime}$ terminal guanosine triphosphate as well as diphosphate was detected in this study, but no protein synthesis initiation codon was present within the first 25

\title{
A larger Gondwanaland?
}

\section{from Peter $J$. Smith}

Geomagnetism Correspondent

Althovgr the principal features of the ancient supercontinent of Gondwanaland are now widely accepted, there are still some details (if whole countries may be so regarded) and disagreements to be settled. One outstanding problem, for example, concerns the present position of the continental crust which once lay between Australia and India. Somewhat less of a problem in many people's eyes is the nature of the present join between India and the rest of Asia. Dewey and Bird ( $J$. geophys. Res., 75, 2625; 1970) suggested that the Himalayas resulted from continental collision; and such has been the influence of the article in which this proposal appeared that some of the difficulties with this interpretation have perhaps not been given the attention they deserve.

At least, that seems to be the view of Crawford (Science, 184, 1179 ; 1974) who cites Meyerhoff's claim (J. Geol., 78, 1; 1970) that there is evidence against India's colliding with the rest of Asia. Certainly, there are problems here, which is why Powell and Conaghan

\section{$5^{\prime}$ terminal residues sequenced.}

Shimotohno and Miura (J. molec. Biol., 85, 21-30; 1974) now report that the $5^{\prime}$ sequence of the RNA made by the silkworm virus enzyme is ppAGPy, and this unique sequence is present in the mRNA transcribed from each of the genome fragments. This indicates that transcription to make mRNA begins at the first base of each molecule, reading from the strand with the $3^{\prime} \mathrm{OH}$ sequence $\mathrm{PuCU}$. Perhaps the unusual base at the $5^{\prime}$ end of the complementary chain plays some part as a recognition site for the binding of the polymerase molecule.

It would be interesting to determine whether the 5 -terminal $A$ in mature mRNA is modified, since the presence or absence of such a modification might be used to distinguish between molecules destined to be messengers from those making up progeny genomic RNA. So far studies on reovirus multiplication have shed no light on the distinction between transcription to give mRNA and replication to give double-stranded RNA, nor on how they are controlled relative to one another. Apparently, the presence of poly (A) in the mRNA species cannot be used as a distinguishing feature since reovirus mRNA does not contain this appendage (J. biol. Chem., 248, 7993-7998; 1973).
(Earth planet. Sci. Lett., 20, 1; 1973) recently proposed that although the Himalayan mountain chain is basically of the collision type, it was not formed as a direct result of the collision. But Crawford, who at the time of writing was apparently unfamiliar with the Powell-Conaghan model, goes further in proposing that the Himalayas formed intracontinentally and arguing against collision on the grounds that the Indus Suture Line, "if it is the relic of oceanic subduction preceding collision, lies on the wrong side of the Himalayas".

In Crawford's reconstruction, Gondwanaland was originally larger than is usually supposed and included Tibet, the Tarim Basin block and parts of northern China. It was Tibet, in fact, which lay between India and western Australia in the form of submerged continental crust. The Indus Suture Line is then seen as "a relic of a Permojurassic oceanic opening to the mantle" which closed at the end of the Jurassic. The Himalayas later developed along fractures which had formed parallel to the opening of the Indus Suture Line.

\section{Precursors of strike-slip faulting}

from Peter J. Smith

Geomagnetism Correspondent

THE travel-time residuals of seismic waves - the differences between observed arrival times and the corresponding arrival times computed using a standard Earth model-are due (in addition to random experimental errors) partly to imperfect source determination and partly to differences in velocity between the real Earth and the assumed model. But if at a particular seisograph station the residuals from many sources at many different locations are averaged, the random errors associated with particular wave paths and particular sources should cancel out, thereby making it possible to isolate the common part of the residuals arising from velocity deviations in the crust beneath the station. If the seismic events concerned are also well distributed in time, it should then be possible to determine any secular variations in the near-station contribution to the residuals, and even to determine changes in the near-station crustal velocity (given the source volume). 